\title{
ACUTE ENCEPHALITIS SYNDROME IN CHILDREN WITH SPECIAL REFERENCE TO JAPANESE ENCEPHALITIS: A RETROSPECTIVE ANALYSIS
}

\author{
Arpita Gogoi', Rita Panyang2, Lokajeet Baro3 ${ }^{3}$ Aditi Baruah4, Pritikar Dowerah5 \\ ${ }_{1}^{1}$ Assistant Professor, Department of Paediatrics, Assam Medical College, Dibrugarh. \\ ${ }^{2}$ Assistant Professor, Department of Paediatrics, Assam Medical College, Dibrugarh. \\ ${ }^{3}$ Associate Professor, Department of Paediatrics, Assam Medical College, Dibrugarh. \\ ${ }^{4}$ Associate Professor, Department of Paediatrics, Assam Medical College, Dibrugarh. \\ 5Professor, Department of Paediatrics, Assam Medical College, Dibrugarh.
}

ABSTRACT
BACKGROUND
The north eastern region of India is an endemic area for viral encephalitis that clinically presents as acute encephalitis syndrome
(AES). The Japanese Encephalitis (JE) is the most important causative agent of AES in this region, resulting in considerable morbidity
and mortality every year.

\section{AIMS}

This study was conducted to analyse the aetiology and epidemiology of AES in this region with special reference to Japanese Encephalitis.

\section{SETTINGS AND DESIGN}

This was a retrospective record-based hospital study carried out in the Department of Paediatrics, Assam Medical College and Hospital, Dibrugarh.

\section{METHODS AND MATERIALS}

Records from a two-year period, 1st January 2014 to 31st December 2015, of children admitted with the diagnosis of AES in the paediatric ward were analysed.

\section{STATISTICAL ANALYSIS USED}

Data was entered into and analysed using SPSS for Windows Version 16. Statistical significance was measured using the Chi square test and a p value of less than 0.05 was considered statistically significant.

\section{RESULTS}

The mean age at presentation of AES in children was 5.4 \pm 3.3 years (range 1 month-12 years) with a male:female ratio of 1.5:1. The maximum number of cases presented during the monsoon months of July and August. JE virus was the commonest causative agent accounting for $43.2 \%$ of all cases. Case fatality rate for JE was $20.5 \%$ and the majority of deaths were observed in the age group of 5 to 12 years. Scrub typhus was isolated from $3.4 \%$ of cases of non-JE AES.

\section{CONCLUSION}

Japanese Encephalitis accounts for a majority of cases of AES in this region with a high mortality rate. Though JE vaccine has been introduced in the National Immunization Schedule (NIS), vaccine efficacy and coverage are issues that need to be addressed as effective vaccination combined with improved vector control strategies and public awareness will be helpful in reducing the disease burden of Japanese Encephalitis.

\section{KEYWORDS}

Encephalitis, Japanese; Encephalitis, Viral; Japanese Encephalitis Vaccines.

HOW TO CITE THIS ARTICLE: Gogoi A, Panyang R, Baro L, et al. Acute encephalitis syndrome in children with special reference to Japanese encephalitis: a retrospective analysis. J. Evolution Med. Dent. Sci. 2016;5(51):3289-3294, D0I: 10.14260/jemds/2016/762

\section{INTRODUCTION}

Encephalitis refers to an inflammatory process affecting the brain. According to the World Health Organization (WHO) clinical case definition, Acute Encephalitis Syndrome (AES) is

Financial or Other, Competing Interest: None.

Submission 09-05-2016, Peer Review 04-06-2016,

Acceptance 10-06-2016, Published 25-06-2016.

Corresponding Author:

Dr. Arpita Gogoi,

C/O Premadhar Borgohain (Advocate),

TR Phukan Road,

Chiring Chapori,

Dibrugarh-786001

Assam.

E-mail: arpitag1000@yahoo.com

DOI: $10.14260 /$ jemds $/ 2016 / 762$ defined as the acute-onset of fever with change in mental status including symptoms such as confusion, disorientation, coma or inability to talk and/or often with new onset of seizures (Excluding simple febrile convulsion) in a person of any age at any time of the year. ${ }^{1}$ AES may present as encephalitis, meningo-encephalitis or meningitis and may be caused by viruses, bacteria, mycobacteria, rickettsia and rarely by toxoplasma. Viral infections are the most common and important cause of encephalitis. Cerebral malaria and noninfectious causes of encephalopathy are required to be excluded while considering AES. Japanese Encephalitis (JE) and Dengue are more prevalent in South East Asia presented as AES. As a part of efforts to control JE, the World Health Organization (WHO) is providing a set of standards for JE 
surveillance, which require the identification of patients with AES as per definition given by $\mathrm{WHO}^{1}$

JE is the most prevalent and significant mosquito borne viral encephalitis of man occurring with an estimated 30,000 to 50,000 of cases and 15,000 deaths annually. About $20 \%$ to $30 \%$ of JE cases are fatal and $30-50 \%$ result in permanent neuropsychiatric sequelae. ${ }^{2}$ Children remain the main victims of the disease. Nearly all states of India have reported JE cases except that of Jammu and Kashmir, Himachal Pradesh and Uttaranchal. ${ }^{3}$ Most JE infections are asymptomatic and the ratio of symptomatic to asymptomatic infections ranges from 1 in 300 to 1 in 1000. The North Eastern Region of India, particularly the upper Assam has been experiencing recurrent episodes of JE with different magnitudes from July to October every year. ${ }^{4}$ Confirmation of diagnosis of JE is usually done by specific titres of IgM antibodies in serum and/or in CSF during acute illness of a suspected AES case. ${ }^{2}$

JE is caused by a zoonotic flavivirus and it is difficult to eradicate because it is transmitted from natural reservoirs like pigs, waddling birds such as cattle egrets, which are important amplifying hosts and man is involved as an accidental host. JE has been controlled effectively through vaccination programs in several Asian countries like Japan, Korea, China and Thailand. ${ }^{4}$ Mortality and morbidity due to JE can be reduced significantly by early diagnosis and appropriate supportive care as presently no definite treatment is available. The present study is carried out with the objective to evaluate the clinico-demographic profile of hospitalized paediatric AES cases to determine the incidence and outcome of acute encephalitis syndrome to document what proportion of these cases are serology proven JE with case fatality and the efficacy of the JE vaccine.

\section{MATERIALS AND METHODS}

This is a record based retrospective descriptive study carried out in children up to 12 years with clinical diagnosis of AES admitted in paediatric wards of Assam Medical College and Hospital, Dibrugarh, for a period of 2 years from January 2014 to December 2015. This is a tertiary level hospital and provides health care services to nearby district along with neighbouring state Nagaland and Arunachal Pradesh. Most patients are referred to this apex level institute from periphery because of lack of neuroimaging and intensive care facilities in the periphery.

During these 2 years' period, 445 children admitted who were fulfilling clinical criteria of AES according to WHO case definition. Patients were categorized on the basis of predominant clinico-investigational picture suggestive of acute encephalitis syndrome.

Data for the study was retrieved from the Hospital's admission and acute encephalitis syndrome record register. A paediatrician is available for consultation round-the clock in the ward under the guidance of senior consultants. Data extracted from the records included age, sex, demographic profile, JE positivity, vaccination status/outcome.

Data collected was entered into a spreadsheet using SPSS software package version 16.0. Descriptive statistics was used to analyse the obtained data. Statistical significance was measured using the Chi square test and a $p$ value of less than 0.05 was considered statistically significant.

\section{Inclusion Criteria}

All paediatric patients up to 12 years of age brought to Assam Medical College and fulfilling the standard WHO case definition of AES as mentioned above were included in the study.

\section{Exclusion Criteria}

This included patients presented like AES picture, but with clinico-investigational diagnosis confirmative of cerebral malaria, Reye syndrome or other non-infectious encephalopathy.

\section{RESULTS AND OBSERVATIONS}

During the study period of two years, the total number of admissions was 10762, with 6201 female (57.6\%) and 4561 males (42.3\%). The total number of clinically diagnosed Acute Encephalitis Syndrome (AES) patients was 445, as per WHO criteria. Thus, the overall percentage of acute encephalitis cases among all admissions was $4.13 \%$. Of these 445 cases, 23 patients had unknown JE status or JE not done and 15 patients had equivocal results. Thus these 38 patients were excluded from analysis and 407 cases were analysed. Of these, 247 cases $(60.7 \%)$ were male and 160 (39.3) were female respectively (Table 1). The male-to-female ratio was $1.5: 1$ and this difference was not statistically significant $(\mathrm{p}=0.654)$.

A total of 176 patients (43.2\%) were found to be JE positive, thus making JE the commonest cause of AES across all age groups of children in this region. Out of this, 109 were males (61.9\%) and 67 were females (38.1\%) respectively.

The mean age at presentation was $5.4 \pm 3.3$ years (range 1 month-12 years). The maximum number of AES cases were reported in the age group of 5 to 12 years with 227 (55.8\%) cases in this age bracket and $122(54 \%)$ of these were found to be positive for JE. (Tables 2, 3). This was found to be statistically significant $(\mathrm{p}<0.05)$.

The majority of AES cases were reported from Dibrugarh (35.1\%) followed by Tinsukia (27.8\%), Sivasagar (16.5\%) and Dhemaji (12.3\%). The remaining $4.1 \%$ of cases were referred from the districts of Lakhimpur, Jorhat and Golaghat (Table 4). Also, the nearby states of Nagaland $(0.5 \%)$ and Arunachal Pradesh (3.7\%) accounted for $4.2 \%$ of all AES cases. JE positivity was maximum among AES cases from Dhemaji district with 41 out of 50 AES patients (82\%) being reported as JE positive. This was followed by the neighbouring state of Arunachal Pradesh from where $46.7 \%$ of AES cases turned out to be JE positive (Table 4, Figure 1).

It is evident that a larger number of AES (as well as JE) cases presented during the monsoon months of July (39.7\%) and August (18.5\%) (Table 5, Figure 2a, 2b). Furthermore, of these AES cases, JE was also maximally reported during these two months with 122 and 35 JE positive cases in July and August respectively. This was found to be highly significant statistically $(\mathrm{p}<0.05)$.

Table 6 shows the year-wise distribution of AES cases during the two years of study, 2014 and 2015. JE positivity in 2014 was $47.1 \%$ ( 82 out of 174 AES cases), while it was $40.3 \%$ (94 cases out of 233) in 2015. This was not statistically significant $(\mathrm{p}=0.172)$ (Figure $3 a, b)$.

There was no statistically significant difference in the occurrence of AES and JE in different communities (Ethnic Assamese, tea garden labourers, others) and religions. Though patients from a rural background accounted for $53.8 \%$ of all 
AES cases and $59.7 \%$ of all JE positive cases, this difference was also insignificant statistically ( $\mathrm{p}=0.107)$ (Table 7).

Analysis of the vaccination status of the cases showed a poor percentage $(8.8 \%)$ of JE vaccination among these cases admitted with AES. This is despite the efforts by the government to incorporate JE vaccination into the Routine Immunization Programme. Even among the patients who were found to be JE positive, JE vaccination was confirmed on history in 23 (13.1\%) cases (Table 8).

The mean duration of hospital stay of these cases was found to be $7.22 \pm 5.14$ days (Range 1 to 29 days). The average duration of stay among non-JE AES cases was less than that of JE cases, which was statistically significant $(\mathrm{p}=0.000)$. Among non-JE cases, 133 (557.6\%) had a hospital stay of less than 7 days, whereas among JE cases $80(45 \%)$ had a stay duration of 7-14 days (Table 9).

In our study, out of 407 AES cases 261 (64.3\%) were discharged, 89 (21.9\%) died, 54 (13.3\%) left against medical advice and $2(0.5 \%)$ were referred to higher centres. Out of the 89 deaths, maximum number of deaths were found in the months of July (28, i.e. $31.5 \%$ ) and August (20, i.e. $22.4 \%$ ). Of the 28 deaths in July, 24 were JE positive and 13 out of the 20 deaths in the month of August were JE positive. Overall, 36 (40\%) of all AES deaths were due to JE. Of all patients diagnosed to be JE positive, the mortality was $20.5 \%$ (i.e. 36 out of 176 JE positive cases) (Table 10).

In our study it can be seen that scrub typhus was the most important infective cause of AES, second only to Japanese Encephalitis in our region. There were 14 (3.4\%) cases of scrub typhus among the AES cases. Dengue virus was isolated in sera of 4 patients with AES. Streptococcus pneumoniae and Haemophilus influenza were isolated from the CSF of one patient each (Table 11).

\begin{tabular}{|c|c|c|c|c|c|c|}
\hline \multirow{3}{*}{ Sex } & \multicolumn{4}{|c|}{ AES Cases } & \multirow{2}{*}{\multicolumn{2}{|c|}{ Total }} \\
\hline & \multicolumn{2}{|c|}{ Non-JE } & \multicolumn{2}{|c|}{ JE } & & \\
\hline & No. & $\%$ & No. & $\%$ & No. & $\%$ \\
\hline Male & 138 & 59.7 & 109 & 61.9 & 247 & 60.7 \\
\hline Female & 93 & 40.3 & 67 & 38.1 & 160 & 39.3 \\
\hline Total & 231 & 100 & 176 & 100 & 407 & 100 \\
\hline
\end{tabular}

$\mathrm{X} 2=.201, \mathrm{df}=1, \mathrm{P}$ value $=.654$

\begin{tabular}{|c|c|c|c|c|c|c|c|c|}
\hline \multirow{3}{*}{ Sex } & \multicolumn{6}{|c|}{ Age } & \multirow{3}{*}{\multicolumn{2}{|c|}{ Total }} \\
\hline & \multicolumn{2}{|c|}{$\begin{array}{c}\text { Below } 1 \\
\text { year }\end{array}$} & \multicolumn{2}{|c|}{$1-5$ years } & \multicolumn{2}{|c|}{$\begin{array}{c}\text { Above } 5 \\
\text { years }\end{array}$} & & \\
\hline & No. & $\%$ & No. & $\%$ & No. & $\%$ & & \\
\hline Male & 26 & 66.7 & 82 & 58.2 & 139 & 61.2 & 247 & 60.7 \\
\hline Female & 13 & 33.3 & 59 & 41.8 & 88 & 38.8 & 160 & 39.3 \\
\hline Total & 39 & 100 & 141 & 100 & 227 & 100 & 407 & 100 \\
\hline Tab & 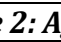 & $a n$ & Gend & $W$ & Dist! & butio & of $\mathrm{Ca}$ & \\
\hline
\end{tabular}

$\mathrm{X} 2=.992, \mathrm{df}=2, \mathrm{p}$ value $=.609$ not significant

\begin{tabular}{|c|c|c|c|c|c|c|}
\hline \multirow{2}{*}{ Age Group } & \multicolumn{4}{|c|}{ AES Cases } & \multirow{2}{*}{ Total } \\
\cline { 2 - 6 } & Non-JE & \multicolumn{3}{|c|}{ JE } & \multicolumn{2}{|c|}{} \\
\cline { 2 - 6 } & No. & $\mathbf{\%}$ & No. & $\mathbf{\%}$ & No. & $\mathbf{\%}$ \\
\hline Below 1 year & 35 & 15.2 & 4 & 2.3 & 39 & 9.6 \\
\hline 1-5 years & 91 & 39.4 & 50 & 28.4 & 141 & 34.6 \\
\hline Above 5 years & 105 & 45.5 & 122 & 69.3 & 227 & 55.8 \\
\hline Total & $\mathbf{2 3 1}$ & $\mathbf{1 0 0}$ & $\mathbf{1 7 6}$ & $\mathbf{1 0 0}$ & $\mathbf{4 0 7}$ & $\mathbf{1 0 0}$ \\
\hline \multicolumn{6}{|c|}{ Jable 3: Age-Wise Distribution of AES Cases: } \\
JE an-JE \\
\hline
\end{tabular}

$\mathrm{X} 2=32.15, \mathrm{df}=3, \mathrm{p}$ value $=.000$ significant

\begin{tabular}{|c|c|c|c|c|c|c|}
\hline \multirow{3}{*}{ District/Place } & \multicolumn{4}{|c|}{ AES Cases } & \multirow{2}{*}{\multicolumn{2}{|c|}{ Total }} \\
\hline & \multicolumn{2}{|c|}{ Non-JE } & \multicolumn{2}{|c|}{ JE } & & \\
\hline & No. & $\%$ & No. & $\%$ & No. & $\%$ \\
\hline Nagaland* & 2 & .9 & 0 & 0 & 2 & .5 \\
\hline Golaghat & 2 & .9 & 1 & .6 & 3 & .7 \\
\hline Jorhat & 4 & 1.7 & 3 & 1.7 & 7 & 1.7 \\
\hline Lakhimpur & 5 & 2.2 & 2 & 1.1 & 7 & 1.7 \\
\hline $\begin{array}{l}\text { Arunachal } \\
\text { Pradesh* }\end{array}$ & 8 & 3.5 & 7 & 4 & 15 & 3.7 \\
\hline Dhemaji & 9 & 3.9 & 41 & 23.3 & 50 & 12.3 \\
\hline Sivsagar & 42 & 18.2 & 25 & 14.2 & 67 & 16.5 \\
\hline Tinsukia & 62 & 26.8 & 51 & 29 & 113 & 27.8 \\
\hline Dibrugarh & 97 & 42 & 46 & 26.1 & 143 & 35.1 \\
\hline Total & 231 & 100 & 176 & 100 & 407 & 100 \\
\hline \multicolumn{7}{|c|}{$\begin{array}{l}\text { Table 4: District-Wise Distribution of AES Cases } \\
\text { (Including Arunachal Pradesh and Nagaland) }\end{array}$} \\
\hline
\end{tabular}

$\mathrm{X} 2=42.202, \mathrm{df}=8, \mathrm{p}$ value $=.000$ significant .

\begin{tabular}{|c|c|c|c|c|c|c|}
\hline \multirow{3}{*}{ Months } & \multicolumn{4}{|c|}{ AES Cases } & \multirow{2}{*}{\multicolumn{2}{|c|}{ Total }} \\
\hline & \multicolumn{2}{|c|}{ Non-JE } & \multicolumn{2}{|c|}{ JE } & & \\
\hline & No. & $\%$ & No. & $\%$ & No. & $\%$ \\
\hline Jan & 11 & 4.8 & 0 & 0 & 11 & 2.7 \\
\hline Feb & 11 & 4.8 & 0 & 0 & 11 & 2.7 \\
\hline Mar & 11 & 4.8 & 0 & 0 & 11 & 2.7 \\
\hline Apr & 9 & 3.9 & 0 & 0 & 9 & 2.2 \\
\hline May & 15 & 6.5 & 1 & .6 & 16 & 3.9 \\
\hline Jun & 16 & 6.9 & 6 & 3.4 & 22 & 5.4 \\
\hline Jul & 39 & 16.9 & 122 & 69.7 & 161 & 39.7 \\
\hline Aug & 40 & 17.3 & 35 & 20 & 75 & 18.5 \\
\hline Sep & 25 & 10.8 & 4 & 2.3 & 29 & 7.1 \\
\hline Oct & 20 & 8.7 & 3 & 1.1 & 22 & 5.4 \\
\hline Nov & 18 & 7.8 & 5 & 2.9 & 23 & 5.7 \\
\hline Dec & 16 & 6.9 & 0 & 0 & 16 & 3.9 \\
\hline Total & 231 & 100 & 176 & 100 & 407 & 100 \\
\hline & 5: $M o$ & 1-wise & 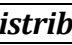 & on of & SS Cas & \\
\hline
\end{tabular}

Chi square 1.503 , df 11 , p 0.000 significant

\begin{tabular}{|c|c|c|c|c|c|c|}
\hline \multirow{2}{*}{ Year } & \multicolumn{4}{|c|}{ AES Cases } & \multirow{2}{*}{ Total } \\
\cline { 2 - 6 } & \multicolumn{2}{|c|}{ Non-JE } & \multicolumn{2}{|c|}{ JE } & \multicolumn{2}{|c|}{} \\
\cline { 2 - 6 } & No. & $\%$ & No. & \% & No. & \% \\
\hline 2014 & 92 & 39.8 & 82 & 46.6 & 174 & 42.8 \\
\hline 2015 & 139 & 60.2 & 94 & 53.4 & 233 & 57.7 \\
\hline Total & $\mathbf{2 3 1}$ & $\mathbf{1 0 0}$ & $\mathbf{1 7 6}$ & $\mathbf{1 0 0}$ & $\mathbf{4 0 7}$ & $\mathbf{1 0 0}$ \\
\hline \multicolumn{6}{|c|}{ Table 6: Year-Wise Distribution of } \\
AES Cases (2014 and 2015) \\
\hline
\end{tabular}

Chi square 1.867 , df 1 , p 0.172 not significant

\begin{tabular}{|c|c|c|c|c|c|c|}
\hline \multirow{2}{*}{ Community } & \multicolumn{4}{|c|}{ AES Cases } & \multicolumn{2}{|c|}{ Total } \\
\cline { 2 - 6 } & \multicolumn{2}{|c|}{ Non-JE } & \multicolumn{2}{|c|}{ JE } & \multicolumn{2}{|c|}{} \\
\cline { 2 - 6 } & No. & $\mathbf{\%}$ & No. & $\%$ & No. & $\%$ \\
\hline Ethnic & 82 & 35.5 & 69 & 39.2 & 151 & 37.1 \\
\hline Teagarden & 95 & 41.1 & 62 & 35.2 & 157 & 38.6 \\
\hline Others & 54 & 23.4 & 45 & 25.6 & 99 & 24.3 \\
\hline Total & $\mathbf{2 3 1}$ & $\mathbf{1 0 0}$ & $\mathbf{1 7 6}$ & $\mathbf{1 0 0}$ & $\mathbf{4 0 7}$ & $\mathbf{1 0 0}$ \\
\hline Table 7a: Community-Wise Distribution of AES Cases \\
\hline
\end{tabular}

$\mathrm{X} 2=1.468, \mathrm{df}=2, \mathrm{P}$ value $=.480$

\begin{tabular}{|c|c|c|c|c|c|c|}
\hline \multirow{3}{*}{ Location } & \multicolumn{4}{|c|}{ AES Cases } & \multirow{2}{*}{\multicolumn{2}{|c|}{ Total }} \\
\hline & \multicolumn{2}{|c|}{ Non-JE } & \multicolumn{2}{|c|}{ JE } & & \\
\hline & No. & $\%$ & No. & $\%$ & No. & $\%$ \\
\hline Rural & 114 & 49.4 & 105 & 59.7 & 219 & 53.8 \\
\hline Urban & 57 & 24.7 & 37 & 21.0 & 94 & 23.1 \\
\hline Tea & 60 & 26.0 & 34 & 19.3 & 94 & 23.1 \\
\hline Total & 231 & 100 & 176 & 100 & 407 & 100 \\
\hline \multicolumn{7}{|c|}{ Table 7b: Location-Wise Distribution of AES Cases } \\
\hline
\end{tabular}




\begin{tabular}{|c|c|c|c|c|c|c|}
\hline \multirow{3}{*}{ Religion } & \multicolumn{4}{|c|}{ AES Cases } & \multirow{2}{*}{\multicolumn{2}{|c|}{ Total }} \\
\hline & \multicolumn{2}{|c|}{ Non-JE } & \multicolumn{2}{|c|}{ JE } & & \\
\hline & No. & $\%$ & No. & $\%$ & No. & $\%$ \\
\hline Hindu & 170 & 73.6 & 139 & 79 & 309 & 75.9 \\
\hline Muslim & 11 & 4.8 & 3 & 1.7 & 14 & 3.4 \\
\hline Christian & 40 & 17.3 & 22 & 12.5 & 62 & 15.2 \\
\hline Others & 10 & 4.3 & 12 & 6.8 & 22 & 5.4 \\
\hline Total & 231 & 100 & 176 & 100 & 407 & 100 \\
\hline Table & eli & $-W i$ & st & ion & $E S$ & \\
\hline
\end{tabular}

$\mathrm{X} 2=5.762, \mathrm{df}=3, \mathrm{p}$ value $=.124$

\begin{tabular}{|c|c|c|c|c|c|c|}
\hline \multirow{2}{*}{$\begin{array}{c}\text { JE } \\
\text { Vaccination } \\
\text { Status }\end{array}$} & \multicolumn{4}{|c|}{ AES Cases } & \multicolumn{2}{|c|}{ Total } \\
\cline { 2 - 7 } & Non-JE & \multicolumn{3}{|c|}{ JE } & \multicolumn{2}{|c|}{} \\
\cline { 2 - 7 } & No. & $\mathbf{\%}$ & No. & $\mathbf{\%}$ & No. & $\%$ \\
\hline Not Vaccinated & 217 & 93.9 & 153 & 86.9 & 370 & 90 \\
\hline Vaccinated & 13 & 5.6 & 23 & 13.1 & 36 & 8.8 \\
\hline Unknown & 1 & 0.4 & 0 & 0.0 & 1 & 0.2 \\
\hline Total & $\mathbf{2 3 1}$ & $\mathbf{1 0 0}$ & $\mathbf{1 7 6}$ & $\mathbf{1 0 0}$ & $\mathbf{4 0 7}$ & $\mathbf{1 0 0}$ \\
\hline Table 8: JE Vaccination Status among AES Cases \\
\hline
\end{tabular}

$X 2=7.554, \mathrm{df}=2, \mathrm{p}$ value $=0.23$

\begin{tabular}{|c|c|c|c|}
\hline \multirow{2}{*}{ Duration of Stay } & \multicolumn{2}{|c|}{ AES Cases } & \multirow{2}{*}{ Total } \\
\cline { 2 - 3 } & Non-JE & JE & \\
\hline 0-7 days & 133 & 74 & 207 \\
\hline $7-14$ days & 74 & 80 & 154 \\
\hline$>14$ days & 24 & 22 & 56 \\
\hline Total & $\mathbf{2 3 1}$ & $\mathbf{1 7 6}$ & $\mathbf{4 0 7}$ \\
\hline Table 9: Duration of Hospital Stay \\
\hline
\end{tabular}

Chi square $=30.035$, df 6 , $p$ value $=0.000$

\begin{tabular}{|c|c|c|c|c|c|c|}
\hline \multirow{2}{*}{ Outcome } & \multicolumn{4}{|c|}{ AES Cases } & \multicolumn{2}{|c|}{ Total } \\
\cline { 2 - 7 } & \multicolumn{2}{|c|}{ Non-JE } & \multicolumn{2}{|c|}{ JE } & \multicolumn{2}{|c|}{} \\
\cline { 2 - 7 } & No. & $\mathbf{\%}$ & No. & $\%$ & No. & $\%$ \\
\hline Discharge & 137 & 59.3 & 125 & 71.0 & 261 & 64.3 \\
\hline Death & 53 & 22.9 & 36 & 20.5 & 89 & 21.9 \\
\hline DAMA & 39 & 16.9 & 15 & 8.5 & 54 & 13.3 \\
\hline Referred & 2 & 0.9 & 0 & 0.0 & 2 & 0.5 \\
\hline Total & $\mathbf{2 3 1}$ & $\mathbf{1 0 0}$ & $\mathbf{1 7 6}$ & $\mathbf{1 0 0}$ & $\mathbf{4 0 7}$ & $\mathbf{1 0 0}$ \\
\hline Table 10: Outcome of AES Cases: JE and Non-JE \\
\hline
\end{tabular}

$\mathrm{X} 2=10.130, \mathrm{df}=4, \mathrm{p}$ value $=.038$

\begin{tabular}{|c|c|c|c|}
\hline \multirow{2}{*}{ Other Causes } & \multicolumn{2}{|c|}{ AES } & \multirow{2}{*}{ Total } \\
\cline { 2 - 3 } & Non-JE & JE & \\
\hline Brain tumour & 3 & 0 & 3 \\
\hline Dengue & 4 & 0 & 4 \\
\hline H. Influenza & 1 & 0 & 1 \\
\hline Streptococcal Meningitis & 1 & 0 & 1 \\
\hline Neurocysticercosis & 0 & 1 & 1 \\
\hline Scrub typhus & 14 & 0 & 14 \\
\hline Total & 23 & $\mathbf{1}$ & $\mathbf{2 4}$ \\
\hline Table 11: Other Diagnoses in AES Cases \\
\hline
\end{tabular}

Acute Encephalitis Syndrome in Children with Special Reference to Japanese Encephalitis: A Retrospective Analysis: Figures

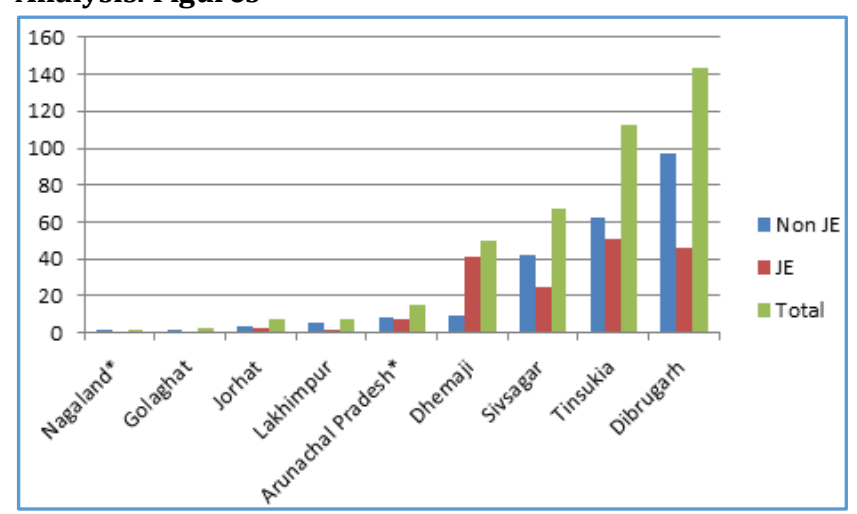

Fig. 1

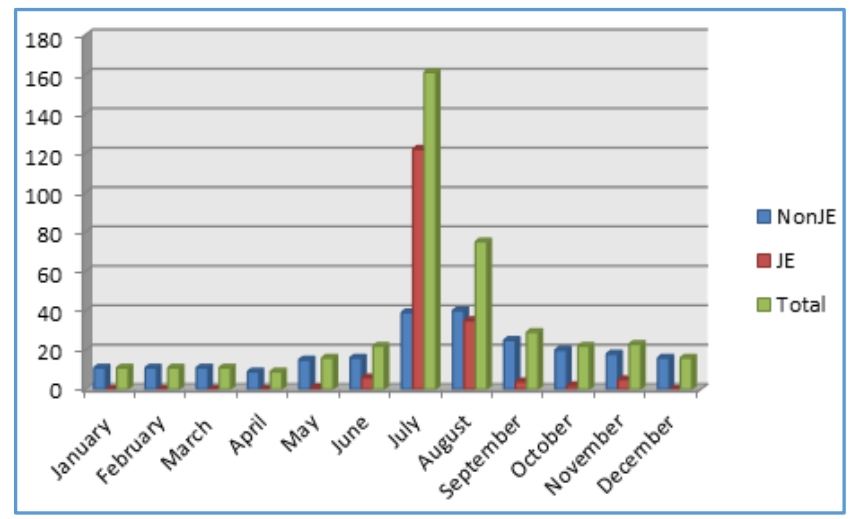

Fig. $2 a$

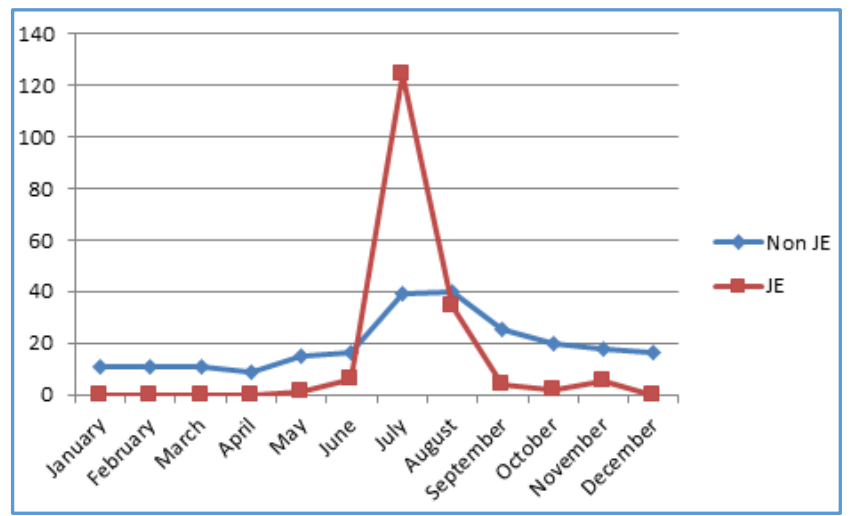

Fig. $2 b$

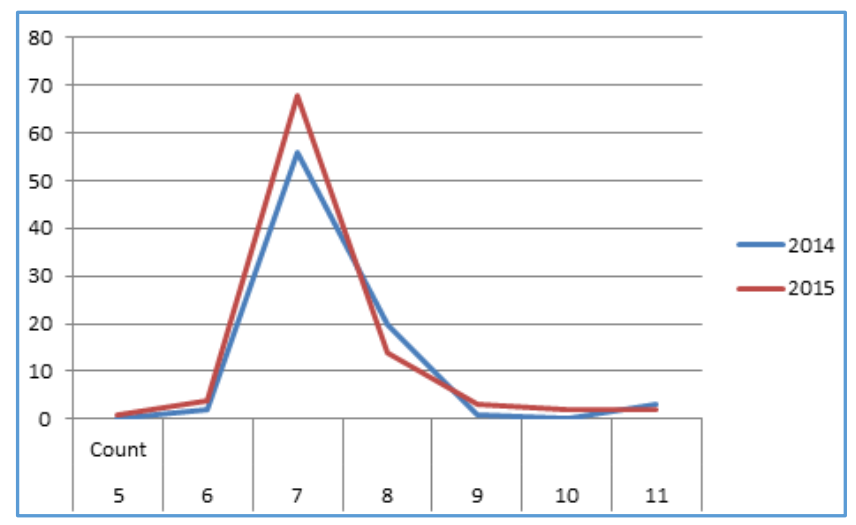

Fig. $3 a$ 


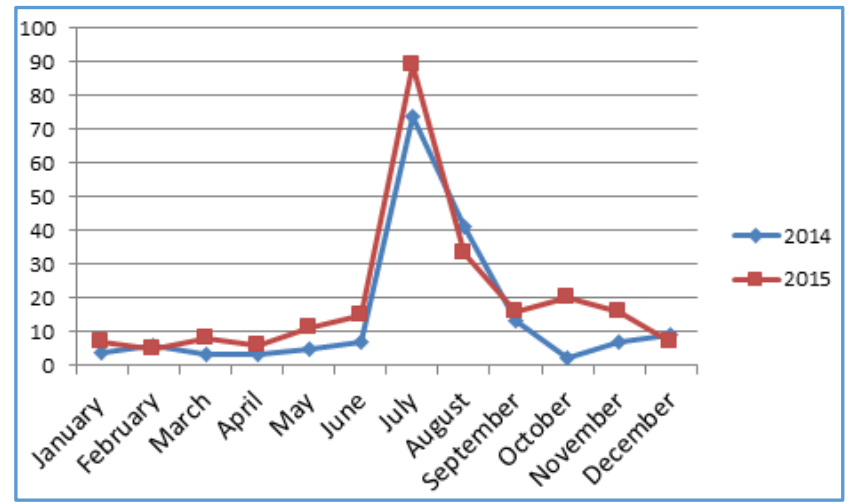

Fig. 3b: Year-Wise Monthly Distribution of JE Positive AES Cases

\section{DISCUSSION}

In the present study, the leading cause of AES in children in this region was found to be Japanese Encephalitis (JE), which accounted for $43.2 \%$ of cases. Similar outcome was also reported from Cuddalore, Tamil Nadu by L. Kabilan et al. ${ }^{5}$

The incidence of AES was found to be more common in males compared to females (59.7\% vs $40.3 \%$ ); and JE among these AES cases was also more in males than in females $(61.9 \%$ vs $38.1 \%$ ). However, these gender differences were not found to be statistically significant. This is similar to the findings from other Indian studies.6,7,8,9 The male predilection for AES (and JE) may be explained by an increased amount of outdoor activities in male children that includes playing outside and also working in rice fields which is the main crop in this region, and hence having a higher chance of being bitten by the Culex tritaeniorhynchus mosquito. ${ }^{9}$ The intermediate hosts, i.e. pigs and cattle egrets are found in abundance in rural areas near paddy field ecosystems in Assam, which play an undeniably important role in the transmission of JE.

In our series, children in the age group of 5 to 12 years were found to be the most frequent group of patients suffering from AES as well as JE compared to the other two age groups namely less than 1 year and 1 to 5 years respectively. This was highly significant statistically and may again be attributed to older children being more exposed to mosquito bites during outdoor activities like playing, school, etc. This is similar to other studies carried out earlier in the subcontinent.8,10 However, in the surveillance study conducted by Kakkar et al in Kushinagar, Uttar Pradesh, AES was found to be commonest in children under five years old. ${ }^{11}$

The district-wise distribution of AES cases in our study showed that it was most common in Dibrugarh district (Where the study was conducted) followed by the neighbouring districts of Tinsukia, Sivasagar and Dhemaji. This might be explained by the fact that these are the nearby areas from where referrals are made to Assam Medical College, which is the apex healthcare institute in this region. Patients from other districts may have been treated in their nearby hospitals and only the worst cases may have been referred here.

The seasonal trend showed the maximal occurrence of cases during the monsoon months of July and August, which is consistent with the finding, the findings of other studies. $8,10,12$ This finding was statistically significant. Children from rural areas were found to be affected more as compared to those from urban areas. These findings are supported by the increased breeding and density of mosquitoes during monsoons, water-logged paddy fields, piggeries in close proximity to homes, non-use of bed nets, etc. ${ }^{13}$ Both cases as well as deaths from JE were reported maximally during the months of July and August. Other studies have also corroborated this finding. ${ }^{12,14}$

The present study was conducted over a two-year period (2014 and 2015), and the year-wise distribution of cases did not show any significant difference between the two years. This is in contrast to the study conducted by Bandhopadhyay et al from West Bengal, where they found a significant reduction in JE cases from 2011 to 2012, which had been attributed to better awareness, mass vaccination against JE etc. ${ }^{14}$

In Assam, JE vaccination with the live SA14-14-2 strain has been incorporated in the National Immunization Schedule (NIS) since the year 2010. Preceding that, mass vaccination was done for children aged 1 to 15 years in a phased manner since May 2006, in order to clear the backlog in the eleven JE endemic districts in Assam (Including Dibrugarh district). ${ }^{15}$

A study of the vaccination status of the AES patients in our study revealed that only $8.8 \%$ of them had received the JE vaccine. This is in sharp contrast to the reported high coverage during the mass campaigns in these districts. ${ }^{16}$ It is also interesting to note that $13.1 \%$ of virologically confirmed JE cases in our study had been given the JE vaccine as well. This raises serious concern over the efficacy of the vaccine used, and the issue of a high vaccine failure rate needs to be addressed urgently. There is a need to also ensure proper coverage of JE vaccination and quality assessment consequently, also they should be evaluated for appropriate corrective measures. ${ }^{17}$ However, it must also be mentioned here that the number of children who had received the JE vaccine may have been underestimated in this study owing to the fact that documentation was not done or not available for verification in most cases, and some children had also received the vaccine during mass vaccination campaigns carried out in schools.

In our study, the mean duration of hospital stay was found to be $7.2 \pm 5.1$ days with a range of 1 to 29 days. The mean duration of hospital stay in patients who died was shorter at $4 \pm 4.2$ days. Hospital stay was found to be longer (7-14 days) in JE positive cases than in non-JE cases ( $<7$ days), and this was statistically significant. Similar findings have been reported by Patgiri et al.18 This prolonged stay in JE positive patients may be attributed to prolonged recovery times and also presence of neurological sequelae in these patients.

Analysis of outcome showed that the overall mortality of AES patients was $21.9 \%$ with JE patients having a mortality of $20.5 \%$ and non-JE AES patients having a mortality of $22.9 \%$ respectively. These findings are comparable to other studies. ${ }^{13,19,20}$ However, the study by Roy et al found a higher JE mortality of $54.55 \%$ in children aged 1 month to 12 years. ${ }^{9}$ $71 \%$ of JE patients were found to have been discharged from hospital in our study, but the proportion of these patients having intact neurological survival and the presence of sequelae at the time of discharge could not be studied.

\section{LIMITATIONS OF THE STUDY}

Records of clinical assessment with respect to symptomatology, neurological status and course during hospital stay were not available for analysis. These might have proved to be invaluable for prognostication. Also, sequelae, neurological residual disease and follow-up assessment of 
discharged cases were not studied, as this was a retrospective study carried out with available hospital records. Hence, these aspects were beyond the scope of our study.

\section{CONCLUSION}

It can be surmised from our study that JE remains the most important cause of AES in children in this region of North East India. It also accounts for a high mortality rate (20.5\%), most of which occurs during the monsoon season. Even though JE vaccination has been incorporated in the National Immunization Schedule in these endemic regions, vaccination rates and efficacy are still low. Better public awareness and education, quality vaccination coverage and effective vector preventive strategies are required in order to combat this annual scourge that affects thousands of children and leads to considerable morbidity and mortality.

\section{ACKNOWLEDGEMENT}

We would like to acknowledge the support provided by $\mathrm{Dr}$ Manjit Boruah, Demonstrator of Community Medicine, Assam Medical College, Dibrugarh, for his valuable help in the statistical analysis.

\section{REFERENCES}

1. Solomon T, Thao TT, Lewthwaite P, et al. A cohort study to assess the new WHO Japanese encephalitis surveillance standards. Bull World Health Organ 2008;86(3):178-86.

2. Center for Disease Control and Prevention (CDC). Question and answer about Japanese encephalitis. March 2013.

http://www.cdc.gov/japaneseencephalitis/qa/index.ht $\mathrm{ml}$.

3. World Health Organization (WHO). Immunization, vaccines and biological. March 2013. Cited: 4th May 2016. Available from: World Health Organization, "Japanese encephalitis

vaccines http://www.who.int/immunization/topics/japanese encephalitis/en/index.html.

4. Dutta P, Khan SA, Khan AM, et al. The effect of insecticidetreated mosquito nets (ITMNs) on Japanese encephalitis virus seroconversion in pigs and humans. American Journal of Tropical Medicine and Hygiene 2011;84(3):466-72.

5. Kabilan L, Ramesh S, Srinivasan S, et al. Hospital and laboratory-based investigations of hospitalized children with central nervous system-related symptoms to assess Japanese encephalitis virus aetiology in Cuddalore district, Tamil Nadu, India. Journal of Clinical Microbiology 2004;42(6):2813-5.

6. Karmarkar SA, Aneja S, Khare S, et al. A study of acute febrile encephalopathy with special reference to viral aetiology. Indian J Paediatr 2008;75(8):801-5.

7. Saxena SK, Mishra N, Saxena R, et al. Trend of Japanese encephalitis in North India: evidence from thirty-eight acute encephalitis cases and appraisal of niceties. J Infect Dev Ctries 2009;3(7):517-30.
8. Khinchi YR, Kumar A, Yadav S. Study of acute encephalitis syndrome in children. J Coll Med Sci Nepal 2010;6(1):713.

9. Roy A, Mandal K, Sen S, et al. Study of acute viral meningoencephalitis in children in sub-Himalayan Tarairegion: clinico-epidemiological, aetiological, and imaging profile. Indian J Child Health 2015;2(4):177-81.

10. Gupta N, Chatterjee K, Karmakar S, et al. Bellary, India achieves negligible case fatality due to Japanese encephalitis despite no vaccination: an outbreak investigation in 2004. Indian J Paediatr 2008;75(1):31-7.

11. Kakkar M, Rogawski ET, Abbas SS, et al. Acute encephalitis syndrome surveillance, Kushinagar District, Uttar Pradesh, India, 2011-2012. Emerg Infect Dis 2013;19(9):1361-9.

12. Shrestha SR, Awale $P$, Neupane $S$, et al. Japanese encephalitis in children admitted in Patan hospital. J Nepal Paediatr Soc 2009;29(1):17-21.

13. Kakoti G, Dutta P, Das BR, et al. Clinical profile and outcome of Japanese encephalitis in children admitted with acute encephalitis syndrome. Bio Med Research International Article ID 152656, 2013;2013:5 pages.

14. Bandyopadhyay B, Bhattacharyya I, Adhikary S, et al. Incidence of Japanese encephalitis among acute encephalitis syndrome cases in West Bengal, India. Bio Med Research International Article ID 896749, 2013;2013:5 pages.

15. Vashishtha VM, Choudhury P, Bansal CP, et al. Japanese encephalitis vaccines. In IAP guidebook on immunization 2013-2014. Indian Academy of Paediatrics Gwalior 2014.

16. Immunization Division Department of Family Welfare Ministry of Health and Family Welfare Government of India. Operational Guidelines Japanese Encephalitis Vaccination in India, MoHFW, September 2010. (Cited: $4^{\text {th }}$ May 2016.) Available from: http://www.iapcoi.com/hp/Dec\%2025th/GuidelinesJapaneseEncephalitis,\%20MoHFW,\%20September\%202010[2]. pdf

17. Fourth Biregional Meeting on the Control of Japanese Encephalitis (JE): Report of the Meeting Bangkok, Thailand, 7-8 June 2009. Tech. Rep. WHO, Regional Office for South-East Asia, 2010.

18. Patgiri SJ, Borthakur AK, Borkakoty B, et al. An appraisal of clinicopathological parameters in Japanese encephalitis and changing epidemiological trends in upper Assam, India. Indian J Pathol Microbiol 2014;57(3):400-6.

19. Avabratha KS, Sulochana P, Nirmala G, et al. Japanese encephalitis in children in Bellary Karnataka: clinical profile and sequelae. International Journal of Biomedical Research 2012;3(2):100-5.

20. Gourie-Devi M. Clinical aspects and experience in the management of Japanese encephalitis patients. In: proceeding of the national conference on Japanese encephalitis. Indian Council of Medical Research, New Delhi, India 1984:25-9. 